\title{
A Perspective on Ecological Sustainability In Wuling Mountain Area
}

\author{
Weijun $\mathrm{He}^{1,}$, Xiaoyun $\mathrm{Du}^{1, \mathrm{~b}}$ \\ ${ }^{1}$ Three Gorges University School of College of Economic and Management, Yichang, China \\ a398827404@qq.com, bduring520_dxy@163.com
}

Keywords: Wuling Mountain Area; ecological services; strategy; sustainable development

\begin{abstract}
Wuling Mountain Area is one of the areas which of high importance in the Yangtze River watershed because of its rich ecological capital. A strategy which integrates and the economic development efforts with the environmental protection is of great importance for the sustainable development of the area. In addition this Ecological capital is the key to alivate the poverty in the area.Through field visits combined with the exensive literature review this article analyzed development status of some of key ecological capitals in the area and provided specific recomendations which could be crucial for solving the economic and environmental problems in the area.
\end{abstract}

\section{Introduction}

Ecological service is an integral part of the ecological cycle of the economy, including eco-tourism. Ecological service means comprehensive and reasonable development and utilization of services on the local ecological environment.The development of the resource base, and its development in general will help reduce the economic resources and the intensity of energy consumption, the development of a conservation-oriented society. And it is normal economic operation of the whole cycle ties and protection. ${ }^{[1]}$ Wuling Mountain Area as the primary poverty alleviation pilot area, can play an effective leading and exemplary role for other contiguous destitute areas.

\section{The necessity of ecological services of Wuling Mountain Area Development}

The impact of the service sector is growing with development of China's economy, therefore, increasing attention has been paid to it. For a long time, the cognition of service sector has been in a highly praised stage Which is low energy consumption and light pollution.

But through the test of time and other researchs showed that if we do not focus on the circular economic development of service sector, it will have a huge impact on the ecological environment, such as the damage from tourism to the nature environment, the water pollution from the catering and so on.

For the damage to the ecological environment casued by the development of service secto, some researchers have proposed the concept of "the development of "ecological services" For a long time .There is no uniform definition to the "ecological services", but the development of circular economic is its feature that can not be ingored. The development of ecological services is necessary.

Development of ecological services is an important way to enhance the economic development of Wuling Mountain Area. From 2001 to 2010, GDP and fiscal revenue increased by 3.57 times and 3.73 times, urban and rural residents' income increased by 2.34 times and 2.36 times, financial institutions deposit and loan balances increased by 5.92 times and 3.6 times.And the primary, secondary and tertiary industrial structure adjustment increased from 35:30:35 to 22:37:41, the urbanization rate grew from $16 \%$ to $28 \% .{ }^{[2]}$ As to the tertiary industry,good development in Wuling Mountain Area of Ecological services throughout the Wuling Mountain Area to promote stronger economic development of orderly and effective, providing a powerful guarantee for the Wuling Mountain Area Regional Development and poverty alleviation work. Ecological services is also conducive to the 
development of good mutual cooperation first, second and tertiary industries between, especially for Wuling Mountain Area, the good development of its service industry can effectively improve the ecological area industrial structure.

Development of ecological services is an important means to improve the imbalance of regional economic development. Good development in Wuling Mountain Area of ecological services will effectively enhance the total area of ecological services, thus strengthening industrial cooperation among different regions, reasonable, effective and full use of the resources and advantages of each region, the ecology of the entire Wuling Mountain Area service as a development target, are conducive to better adaptability to the modern area economic developments. Taking Huaihua and Zhangjiajie as examples, the plan clearly makes the two cities as center cities in Wuling Mountain Area. Logistics and Tourism in Huaihua and Zhangjiajie will drive the development of the whole area of logistics and tourism.

Development of ecological services can narrow the income gap between urban residents in one effective way.It will help enhance the residents' income, reduce the income gap between urban and rural residents, improve the entire urbanization of Wuling Mountain Area . Development of ecological services of Wuling Mountain Area is bound to bring more jobs, generate higher income for the local population, and broaden their income sources , thus enhancing the urbanization level across the region.

\section{Development Status and problems of ecological services in Wuling Mountain Area}

Wuling Mountain Area is characterized by deep poverty, weak infrastructure, and imperfect market system. Therefore to promote the development of eco-services in the area is gradual. Implementing the sustainable development strategy is crucial in the area to ensure the sustainability of the ecological capital in the area while expanding the space for economic development. Based on current analysis of development of ecological services in Wuling Mountain Area, the following problems may exist.

(A)Lack of trained human resource. There is lack of trained professionals for effective implementation of sustainable development strategies on the ground.

(B) Ecological development problems of Regional Cooperation of the service sector in The Wuling Mountain Area. ${ }^{[3]}$ Wuling Mountain Area development and poverty alleviation efforts are targeted at the entire Wuling Mountain Area, instead of individual areas. Making this area specific can do a lot in terms of identifying each areas socio-economic and environmental characteristics which could be instrumental designing area specific strategies which fosters cooperation rather than completion.

(C)The presence of regional imbalances in Wuling Mountain Area ecological services. Wuling Mountain Area of the overall ecological services relying on the Hunan, Hubei, Chongqing and level of development, the various provincial cities and counties in Guizhou village, good development of various local ecological services is strong support throughout the area of development. In tourism, for example, the city of Zhangjiajie is now well-known national 5A scenic spot, 2011 GDP up its tourism industry accounted for $54.2 \%$, while the Enshi City in 2011 its tertiary industry accounted for $42.58 \%$ GDP total. Natural scenic Enshi City, such as the Grand Canyon Enshi, Enshi City, and other resorts are very promising.

(D)Pevalence of poor environmental conditions, asymmetric information, and underdeveloped infrastructure. In Guizhou Province, in some remote areas of the city of Tongren due to the lack of basic infrastructures needed for rapid economic devlopnment combined with difficult environmental conditions and assymeteric information are hindering the economic devlopnment in the area.

(E)Ensuring economic devlopnment at the expense of envionment degradation is not sustainable. Our country has long been advocating sustainable development, the same ecological services must unswervingly take the road of sustainable development,.sustainable development which integrates 
the economy and the environmetal protection efforts is the only way people can enjoy the pleasure of mountains and water as always .

\section{Wuling Mountain Area Development Strategy ecological services.}

(A) Strengthen personnel training. Through cooperation with relevant leading enterprises, government can increase the intensity of introduction of talent, to attract more ecologically service personnel for the development of service area of ecological words and ideas.

(B) The strengthening of regional cooperation between the various regions in order to enhance the economic level of the entire area of the goal. Developing the area needs cooperation among the different cities and counties. Cooperation is important to achieve area wide economic development meanwhile, we must continue to tap the economic benefits which are specific to each area.

(C) Improve the infrastructure area. ${ }^{[4]}$ We need to support infrastructure sector, improve the construction of roads, railways, ports, airports, distribution centers and network communications infrastructure and so on.

(D) Development of the economy to increase environmental protection efforts, to ensure sustainable development. The area have huge resource capital and integrating the environmental protection and the economic development is the key to ensure its sustainability.

\section{Conclusion}

Wuling Mountain Area as one of the main battlefield of the national poverty alleviation, solving the areas economic problems is of great concern. The development of ecological services of Wuling Mountain Area there are still many problems, with a much room for improvement. The development of Wuling Mountain Area of ecological services is a gradual process and it will take some time until we see the fruits of pursuing sustainable development strategies.

\section{Acknowledgements}

Funding for this research was provided by the National Social Science Fund (No.13BMZ057). Funding for this research was provided by the Graduate students' Innovation Fund of China Three Gorges University .The authors would like express their gratitude for the support.

\section{References}

[1] Zhu Xi "Wuling Mountain Area Regional Development and Poverty Alleviation Plan (2011-2020)" excerpt [J] national altar, 2012 (15): 8-10.

[2] Juhel,Marc H.The Role of Logistics in Stimulating Economic Development[M].Beijing:Paper Presented at the China Logistics Seminar,1999:25-37.

[3] Cao Liming, flat first done after the development of mountain agricultural product logistics System - A Case Study of Huaihua City, Hunan Province [J] Logistics Engineering and Management, 2010,09: 49-51.

[4] Dai Chuzhou Wuling Mountain Area Development of Ethnic Culture Tourism Industry - Hunan Wuling Mountain Area as an Example [J] Tongren University, ${ }^{3} 2013,01:$ 8-11. 